\title{
Air-Drying: A Simple Method for the Preservation of Hollow Organs and Lungs to Contribute to the Teaching of Anatomy
}

\author{
Mohamed Mohamed Abd El-Rahman Abumandour ${ }^{1}$ (다 \\ ${ }^{1}$ Department of Anatomy and Embryology, Faculty of Veterinary \\ Medicine, Alexandria University, Egypt \\ J Morphol Sci 2019;36:269-278.
}

\author{
Raafat Mohamed Ahmed El-Bakery ${ }^{1}$
}

\begin{abstract}
Keywords

- anatomy

- preservation

- air -drying

- hollow organs

- Lungs
\end{abstract}

\author{
Address for correspondence Mohamed M.A. Abumandour, \\ Department of Anatomy and Embryology, Faculty of Veterinary \\ Medicine, Alexandria University, Rashid, Edfina, Behera, Post Office \\ Box: 22785, Egypt (e-mail: m.abumandour@yahoo.com).
}

\section{Introduction}

Throughout history, many techniques have been used for anatomical preservation. One of the earliest reported methods of human tissue preservation is mummification, which was used by ancient Egyptian civilizations to prepare human remains for burial. This method is based on dehydration, and is preceded by a treatment with chemical substances whose recipe we currently have no exact knowledge of, but some mummies that have been studied by scientists have become quite famous not only for their role in history as individuals, but also due to the wealth of medical information obtained from the mummified bodies. ${ }^{1}$ The most recent technique currently used is plastination. ${ }^{2-4}$

After the advent of mummification, and before the advent of plastination, many methods to preserve hollow organs and lungs were described in published articles, such as preservation with formalin, freeze-drying, and air-drying. However, plastination has recently begun to revolutionize the way in which human and animal gross anatomy can be presented to students. ${ }^{5-7}$

It is well-known that the fixation process is the most important step of all, because it keeps the fixed specimens insoluble and protected against deterioration; therefore in order to study and dissect, the specimens in every anatomical laboratory must be preserved and fixed with a preservative solution. ${ }^{1}$ However, in anatomical laboratories, fungal contamination of the specimens can cause allergy in students and professionals due to the large exposure to airborne fungal spores. ${ }^{8}$

The regular exposure of anatomists and their students to formalin leads to many health problems, such as irritation of the eye and upper respiratory tract, ${ }^{9,10}$ reduction in pulmonary function, ${ }^{11}$ and increased risk of nasal and lung cancer; ${ }^{12}$ moreover, the exposure of females to formalin causes a delay in conception, increases the likelihood of abortion, and may lead to infertility. ${ }^{13}$ Research on animals has confirmed that formalin is a carcinogen. ${ }^{14-16}$ received

June 1, 2019

accepted

June 10, 2019
DOI https://doi.org/

10.1055/s-0039-1695047. ISSN 2177-0298.
Copyright @ 2019 by Thieme Revinter

Publicações Ltda, Rio de Janeiro, Brazil

\section{License terms}

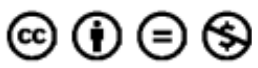


In the present study, we chose the air-drying method due to the low cadaveric availability and limited funds in our anatomical laboratory, and because this method is safe regarding handling. Moreover, we have no means of using the plastination technique, which is very expensive in our developing country of Egypt.

\section{Material and Methods}

\section{Samples}

Fresh hollow organs such as the stomach, the intestines, and the female genital system, as well as the lungs, were collected from different animals (cows, camels, goats and sheep) from a slaughterhouse in the city of Desouk; the organs of horses, donkeys and dogs were also collected, but those animals were brought from farms, anaesthetized, bled well through the common carotid artery, and then had their hollow organs and lungs collected directly.

\section{Air-Drying Pump (Compressor)}

The air-drying pump (compressor) (-Fig. 1) is adjusted to the suitable pressure; then, its tubes are connected to the openings of the hollow organs: the cardiac and pyloric openings in the case of the stomach, the beginning of the duodenum in the intestines, the vulva the female genital tract, and the trachea in the lungs.

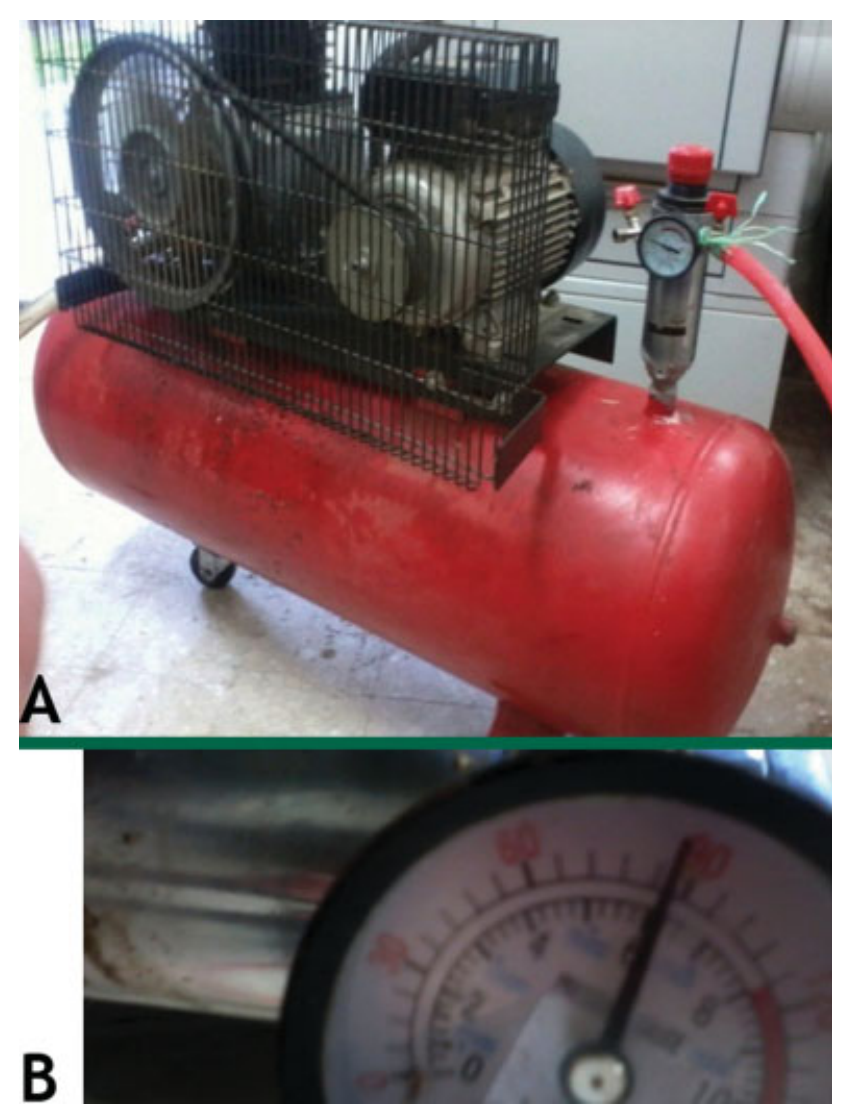

Fig. 1 Photograph of the air-drying pump (compressor).

\section{Preparation of the Samples}

The hollow organs were flushed well with tap water until they were rid of ingesta and any other waste products. The adipose tissue, the omenta, the fat and the mesentery were removed with caution, without damaging the outer muscle layers. The ingesta and waste products of the ruminant stomach should be removed by making small opening, which is then sutured (-Fig. 2). As for the preparation of the lungs, care must be taken to avoid laceration or tearing, and then all blood must be removed by washing, which should be followed by the removal of all fat, excessive connective tissue, and tracheobronchial lymph nodes to quicken the drying process.

Once the hollow organs and lungs have been cleaned, they are ready to be hooked to the air-drying pump (compressor) through cannulation with appropriate-sized tubes for the removal of fluids. Then, the organs are first dilated to the suitable degree of inflation (in relation to their normal size) by controlling the air flow of the pump.

Then, depending on the volume of the organs, they will remain hooked to the pump for a given number of time; the lungs, for example, usually stay hooked to the machine for 7 continuous days, and ruminant stomachs, for 10 to 14 continuous days. One should be careful to avoid increasing the pumping of air to avoid herniation or rupture; the lowest rate of pumping should not be used either, to avoid the closing or shrinking of the organs.

The next step is to inject the lumen of the organs with expanding plastic foam materials such as fiberglass, flexible plastic resin, or silicone, to protect the internal structure from damage by insects or bacteria and prevent collapse during handling.

The last step is applying varnish to the external surface of the hollow organs to protect them from damage by insects or bacteria; in this stage, painting or labeling of certain structures on the external surface of the organs may be performed to aid in the teaching of anatomy (-Fig. 7 and $\mathbf{9}$ ).

\section{Result}

This preservation method is suitable to be used in developing countries because it is very cheap, highly durable, userfriendly, requires no wet preservation or special equipment, and the organs can be subsequently used in the teaching of gross anatomy.

The method involves four phases:

The first phase is the preparation, so that the organs are clean and free from any ingesta, waste products, fat, excessive connective tissue and blood, as shown in (-Figs. 2 and $3 \mathbf{A}$ ). The second phase is the adjustment, adaption and control of the air flow (inflow and outflow) to restore the organs to their natural size; the air flow is then maintained for different periods of time according the size of the organs to help in the replacement of water by compressed atmospheric air, which results in lightweight, dry preserved organs.

The third phase involves the protection from insects or bacterial damage and the prevention of collapse during handling. This is performed through the injection of 

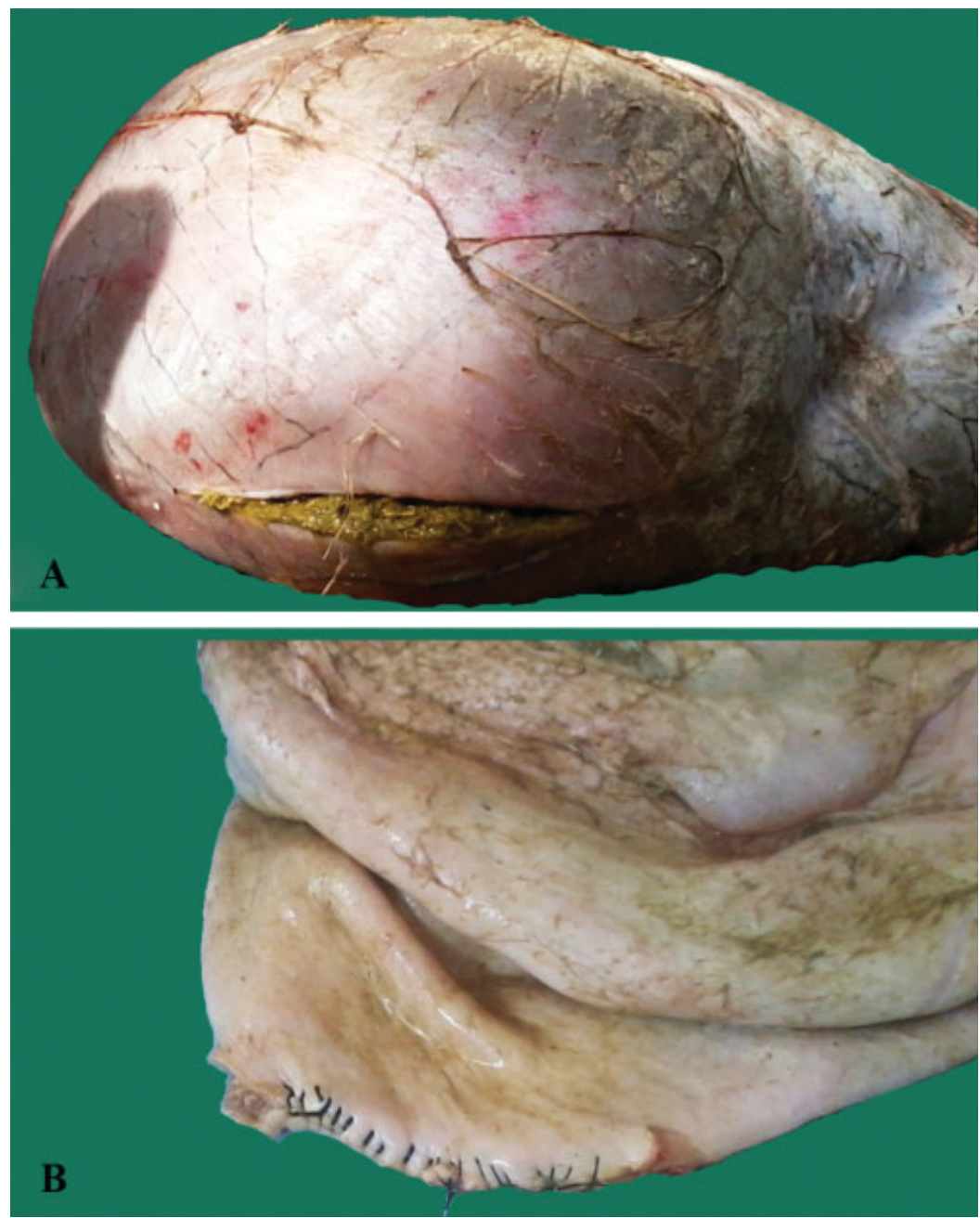

Fig. 2 Photograph of the ruminant rumen to show the cleaning process. View (A): the small opening in the rumen to remove the ingesta. View (B): the suture of the small opening after the rumen is rid of ingesta and any other waste products.

expanding plastic foam materials in the lumen, which is followed by the application of varnish on the external surface to protect the specimens from damage by insects or bacteria. The fourth phase is the painting or labeling of certain structures on the external surface, or the made an opening to show the internal structures for the teaching of anatomy which more clear in the hollow organs such as; the ruminant stomach with its internal structures (ruminal papillae, reticular cell, omasal lamellae of omasum and abomasal folds); the trigenome vesciae of the urinary bladder, the uterine caruncles of uterus, and the margoplicatus line separating the glandular and non-glandular mucous membrane of the horse stomach (-Figs. 4-9).

In anatomical laboratories, this method helps to solve the problem of studying the anatomical points of the gastrointestinal tracts of large animals, especially large ruminants (-Figs. 3-9), because, when the gastrointestinal tract is removed from the abdominal cavity and emptied of ingesta, many important anatomical points are lost, and this poses a large problem to the anatomy students attempting to study the internal structure of these hollow organs.
The present study represents the first attempt to analyze the topographic anatomical position of the lung within the thoracic cage of donkeys. The aim of that is to determine the normal topographic position of the lungs, the area of auscultation and percussion, and to facilitate the study of the relationship of the lungs with their surrounding structures, such as the heart, the ribs, the sternum and the diaphragm. This is achieved by removing all of the thoracic muscles and leaving only the lungs and heart with their covering within the thoracic cage; then, the air-drying preservation method is applied, as shown in (-Fig. 10).

In the case of the lungs, this method enables the visualization of the lobation and of many impressions on the parietal and visceral surfaces that may differ according to the state of the taken lungs (expiration or inspiration); the costal impression, for example, is observed during inspiration, but not during expiration. The border and surface of the lungs will be clear; therefore, by increasing the amount of air pumped into them, the visceral pleura becomes separated, and can be easily observed (- Fig. 8 and $\mathbf{9}$ ).

The preserved organs produced through this method have many advantages: they are stable, have clean surfaces, 

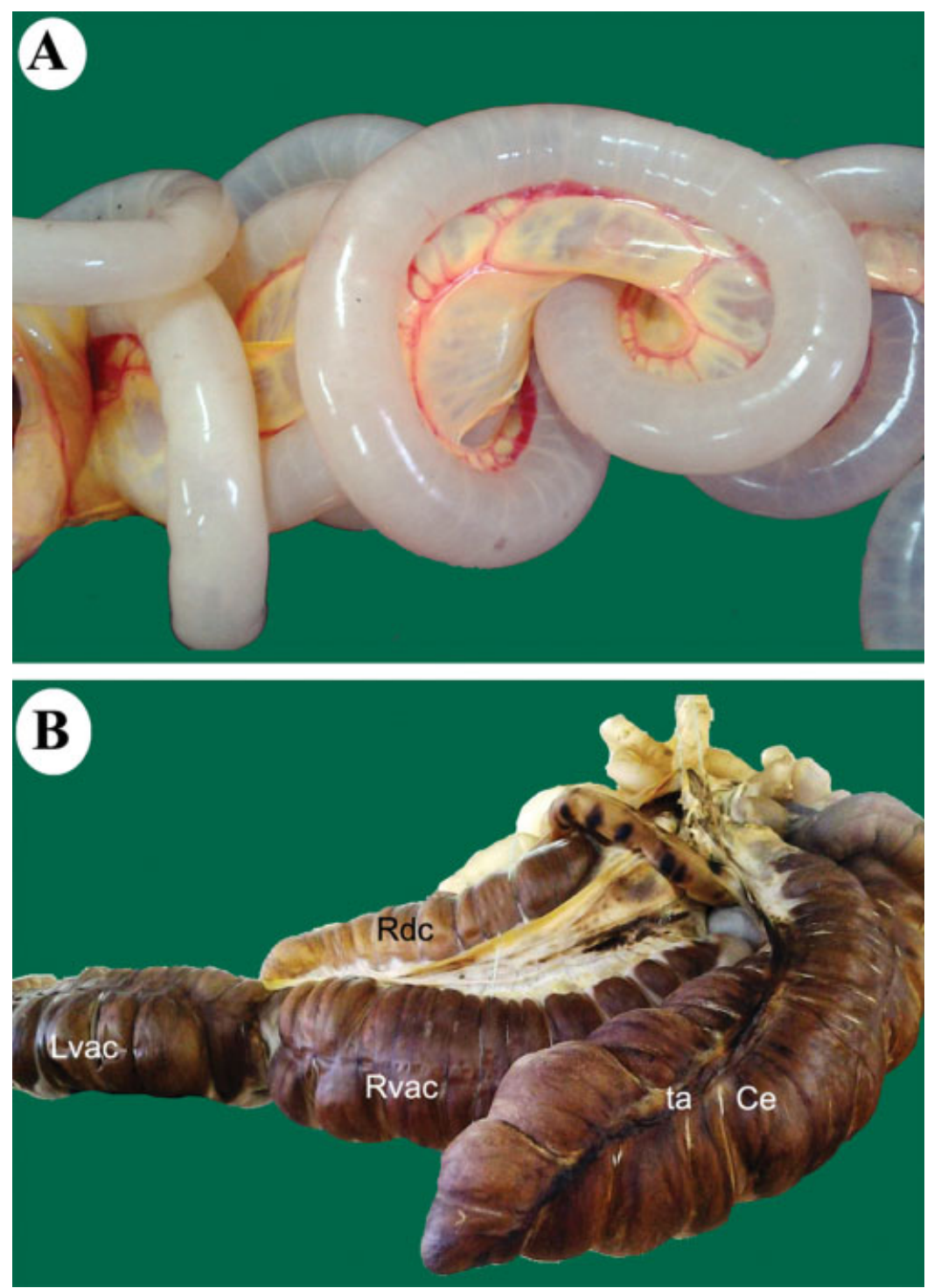

Fig. 3 View A: photograph of the small intestine of a donkey after cleaning with tap water until it was rid of ingesta and any other waste products. View B: photograph of the preserved air-dried large intestine of a horse. Abbreviations: Ca, cecum; ta, lateral taenia; Rvac, right ventral ascending colon; Lvac, left ventral ascending colon; Rdc, right dorsal colon.

no odor, are extremely durable, and maintain their original color and almost their original size through the control of the air that is pumped into them. Additionally, they are dry to the touch, free from any greasy residue, and lighter than they were in their natural state, in which the physical state of the organs were similar to that in the living condition (as shown in -Figs. 4 to 10). Moreover, this method also contributes to the study of the normal anatomical position of the lungs within the thoracic cage in the suspended trunk of donkeys, as shown in (-Fig. 10).

Regarding potential hazards to human health and the environment, the preserved organs can be easily and safely examined without medical gloves, for they do not release odor or toxic fumes, and they do not contain any toxic fixative materials or chemical substances, as shown in (-Fig. 4B, 6C, 8C and 9C).

\section{Discussion}

The present study describes the air-drying method, which is an alternative to prepare the lungs and hollow organs for the study and teaching of gross anatomy. This method of preservation is suitable to be used in developing countries, as it is very cheap to prepare, simple to perform, performed at room temperature $\left(37^{\circ}-40^{\circ} \mathrm{C}\right)$ without the need of special equipment, and produces specimens with many advantages.

Many previous articles in the literature have described different methods to improve the teaching of anatomy, such as the use of: embalmed cadavers, which remains the basic mainstay for the teaching of gross anatomy in most facilities of medicine; ${ }^{17}$ live animals; ${ }^{18}$ prosections versus dissections; ${ }^{19,20}$ learning without cadavers; ${ }^{21}$ problem-based learning; ${ }^{21}$ virtual-reality surgical simulators; ${ }^{22}$ computer- 


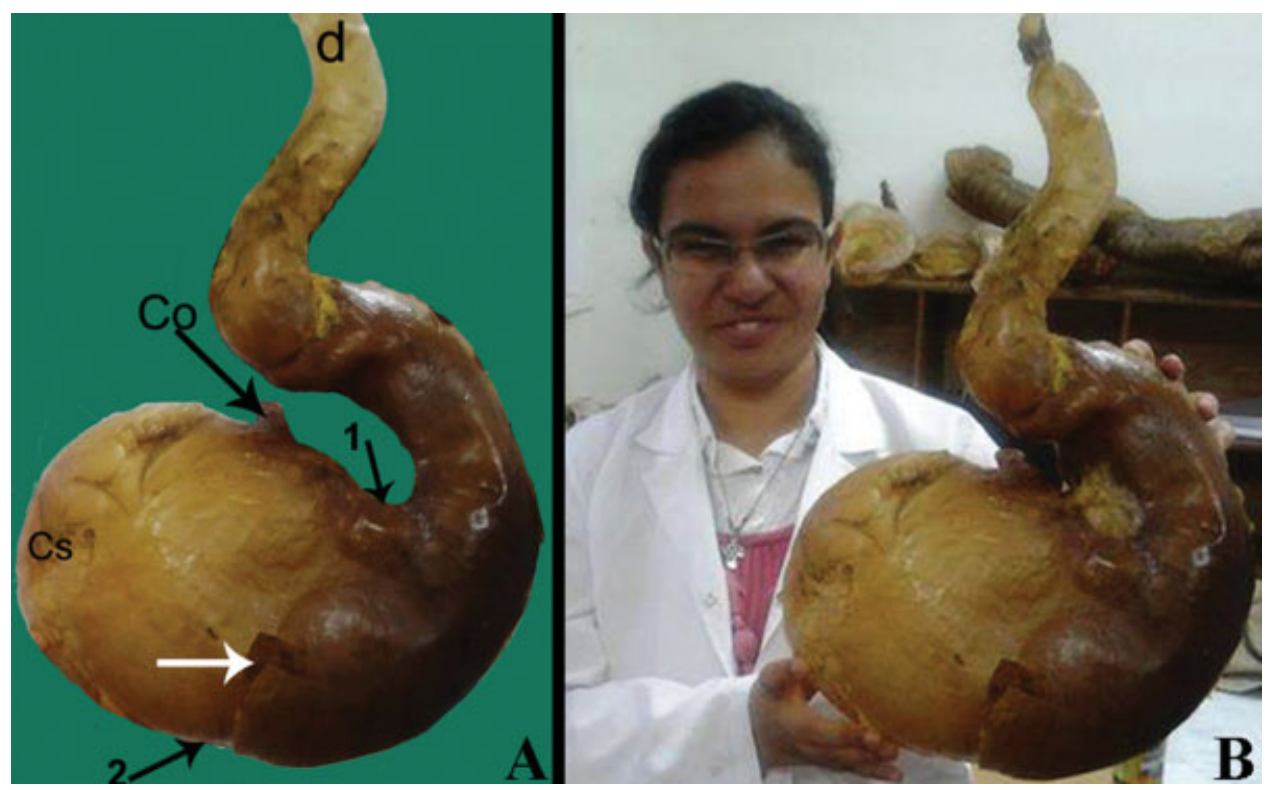

Fig. 4 Photograph of an air-dried preserved horse stomach. View A: external appearance of the stomach; the white arrow indicates the opening on the parietal surface to the internal structure. 1, lesser curvature; 2 , greater curvature. Abbreviations: $C s$, caucus cescus; $d$, duodenum; Co, cardiac opening. View B: to clarify that the preserved stomach is stable, has a clean surface, no odor, is extremely durable, maintains its original size, is dry to the touch, free from any greasy residue, and is lighter than in its natural state.

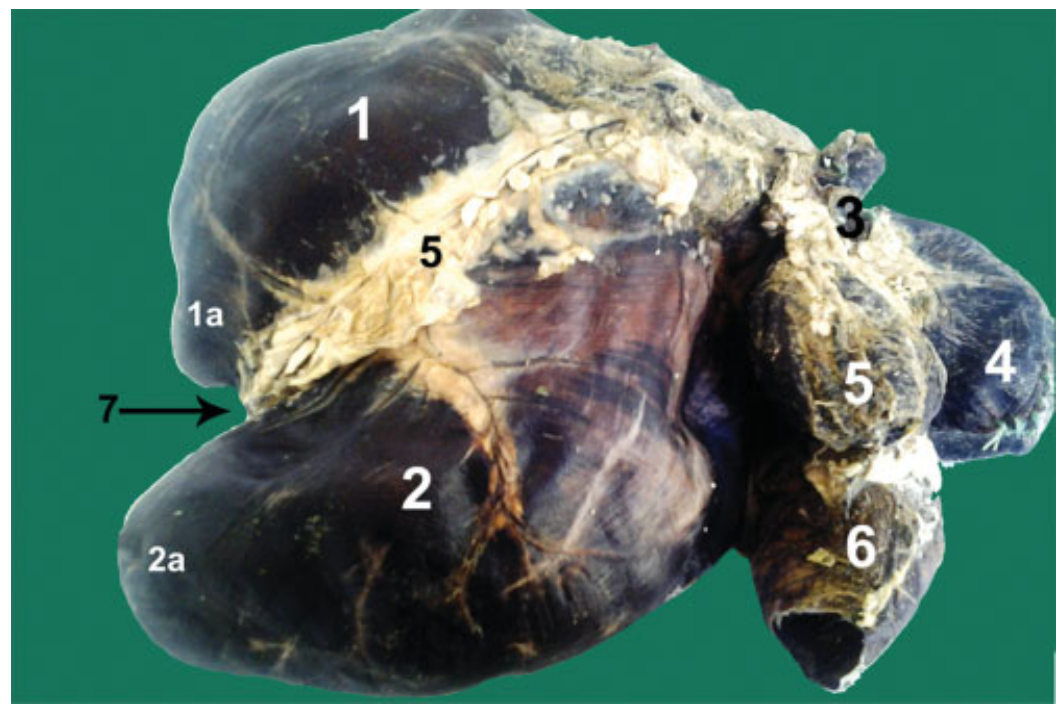

Fig. 5 Photograph of an air-dried preserved stomach of an ox. 1, dorsal ruminal sac; 1a, caudodorsal blind sac; 2, ventral ruminal sac; 2a, caudoventral blind sac; 3 , cardiac opening; 4, omasum; 5, reticulum; 6 , abomasum.

aided instruction; ${ }^{23}$ modular resource centers; ${ }^{24}$ and, finally, plastination, which is the most important technique recently developed for the preservation of biological specimens. ${ }^{4,18}$

As demonstrated in many articles and textbooks, nowadays formaldehyde is the most commonly used chemical substance in developing countries, because it is cheap, has easy penetration, and acts fast. Moreover, formaldehyde solutions are used as a fixative material for gross anatomical, microscopic, histological and pathological specimens, as well as in embalming to disinfect and temporarily preserve human and animal remains. ${ }^{14,25}$

However, formaldehyde causes many recorded healthy problems, and is classified as a human carcinogen; it causes nasopharyngeal cancer and may cause leukemia; it is a toxic, allergenic material that, in rare cases, may induce bronchial asthma when someone is exposed to relatively high doses of it. Moreover its inhalation can cause irritation of the eyes, nose, tunica mucosa, with increased tearing as it is quickly absorbed by the nose and the upper part of the lungs. ${ }^{1,14,15}$ Formaldehyde also causes severe pain, vomiting, coma, and possible death if drunk in large amounts, and it also leads to irritation of the skin (if a strong solution comes into contact with it), but reports of deaths in humans from the short-term inhalation of formaldehyde were not found in the literature. As a result of this, several European countries restrict the use of formaldehyde, including the importation of formaldehyde-treated products, and embalming. As of September 2007, the European Union banned the use of 


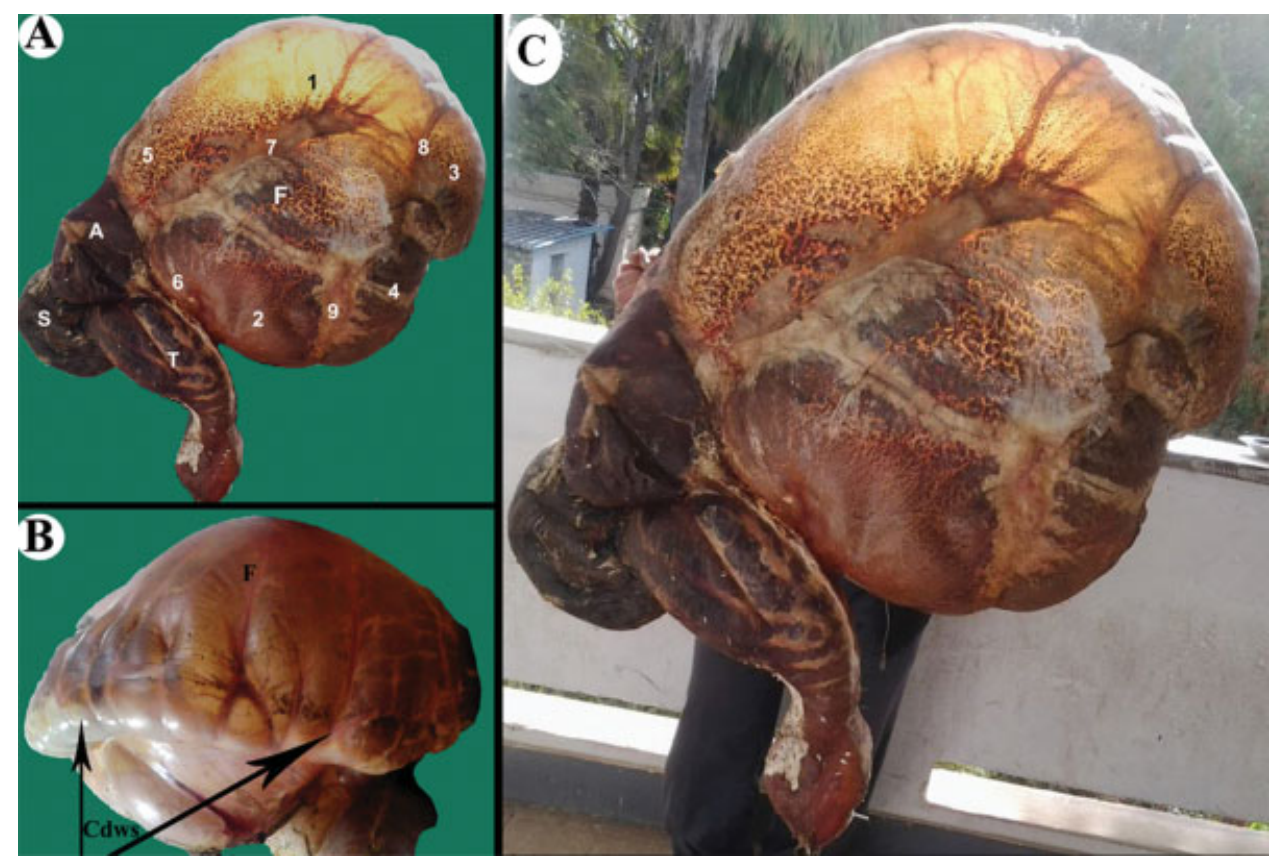

Fig. 6 Photograph of an air-dried preserved stomach of a one-humped camel. View A: 1, dorsal ruminal sac; 2, ventral ruminal sac; 3 , caudodorsal blind sac; 4 , caudoventral blind sac; 5 , ruminal atrium; 6 , ruminal recess; 7 , left longitudinal groove; 8 , dorsal coronary groove; 9 , ventral coronary groove. Abbreviations: A, anterior glandular sac area; F, first compartment; S, second compartment; $\mathrm{T}$, third compartment. View B: Abbreviations: Cdbs, caudodorsal blind sac; Co, cardiac opening; F, first compartment. View C: to clarify that the preserved one-humped camel stomach is stable, has a clean surface, no odor, is extremely durable, maintains its original size, is dry to the touch, free from any greasy residue, and is lighter than in its natural state.

formaldehyde (including in embalming) due to its carcinogenic properties as a biocide, under the Biocidal Products Directive (98/8/EC). ${ }^{26,27}$

In the anatomical, histological and pathological laboratories of developing countries, there is no other way except the use of formaldehyde for the preservation and examination of specimens in the classic display in glass jars. As a result of this, anatomy students will present significant negative health effects due to their exposure to formalin nearly three hours a day; these health effects are not immediate at these low doses, but they insidiously accumulate over time. In addition, the formaldehyde jars are fragile, and immersion in fluid makes viewing difficult; the specimens may be removed for observation, but handling them is unpleasant because of the formaldehyde fumes. Also, upon exposure to air, such specimens quickly lose color, and their surface features progressively deteriorate.

Thus, there are two preservation methods other than the undesirable formalin preservation that are suitable for developing countries. The first method, described by O'Sullivan and Stewart, ${ }^{5}$ is freeze-drying, which produces specimens that can used for nearly 3 years without any signs of deterioration; the disadvantage of this method is that it is not free from contamination by mold. The second method is air-drying, which was used $^{3,28}$ in the present study. The preserved organs produced through this method have many advantages: they are stable, have clean surfaces, no odor, are extremely durable, and maintain their original color and almost their original size through the control of the air that is pumped into them. Additionally, they are dry to the touch, free from any greasy residue, and lighter than they were in their natural state, in which the physical state of the organs were similar to the living condition. Moreover, this method also contributes to the study of the normal anatomical position of the lungs within the thoracic cage in the suspended trunks of donkeys.

Currently, the most desirable method of preservation is plastination, which is unsuitable for developing countries, for it is more expensive and requires special instruments, a special laboratory, and a special chemical substance; in addition, with plastination the preservation process takes longer. Plastination was originally introduced to the medical world by Dr. Gunther von Hagens in 1977. In this process, water and the lipids in the biological tissues are replaced by curable polymers (mostly silicone, epoxy, and polyester), which then will harden and finally result in natural-looking, dry, odorless and durable specimens. ${ }^{29}$ The preserved specimens produced through this methods have many desirable characteristics: they are clean, dry, odorless, and durable biological specimens that can be handled without gloves, and they do not require any special storage conditions or care. These specimens also prevent the exposure of the staff and students to the toxic substances (such as, formaldehyde, phenol and alcohols) used in the classic preservation of biological tissues. ${ }^{2,4,30,31}$

The current study agrees with what is stated in the study by Arnautovic et $\mathrm{al}^{32}{ }^{32}$ who describe that filling the air-dried hollow organs with expanding plastic foam protects their inner surface from insect damage and prevents their collapse during normal handling, while the application of varnish does the same for the external surface. The present study added that the external surface of the organs may be painted or labeled to demonstrate certain anatomical points, and that an opening 

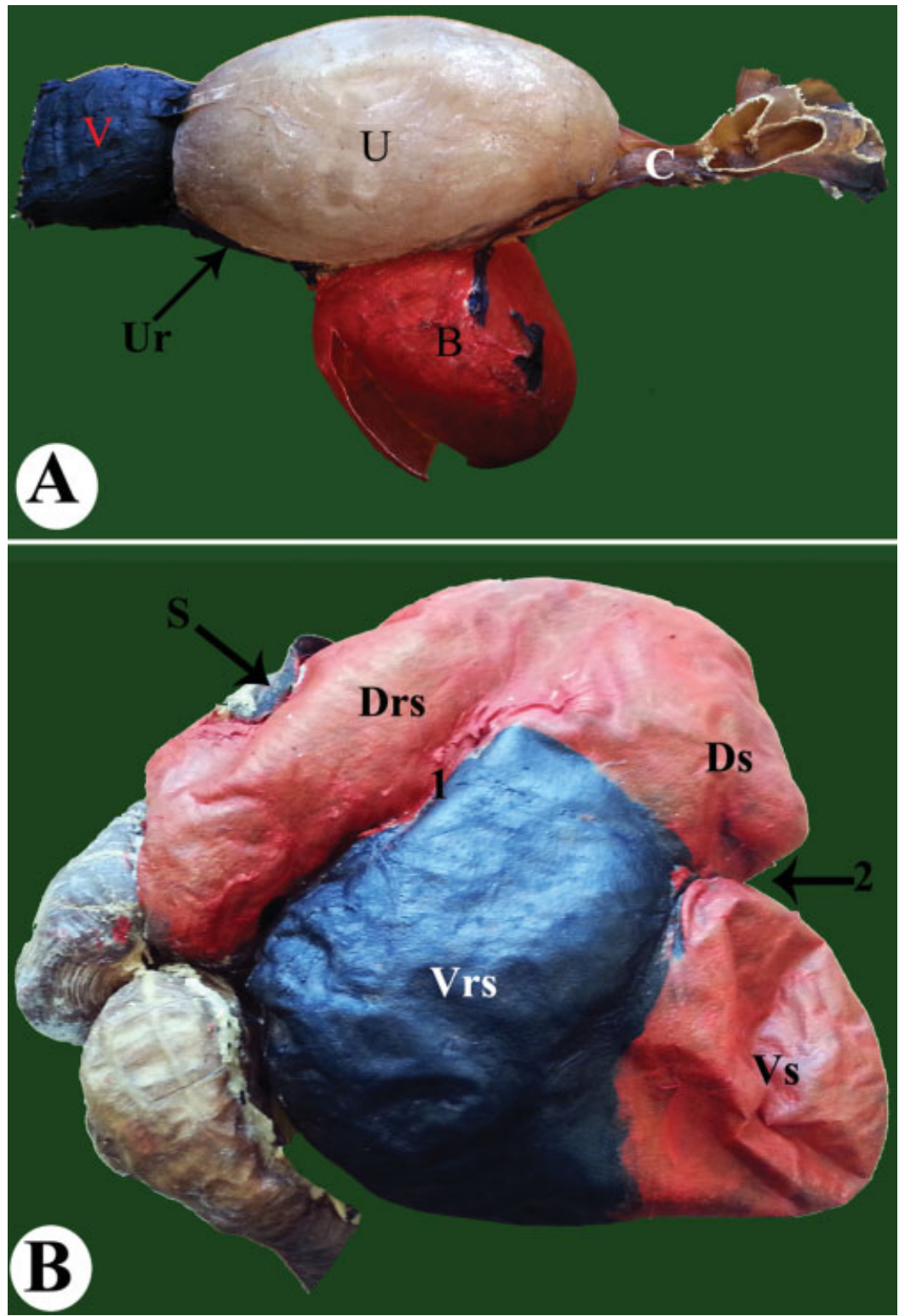

Fig. 7 A: photograph of an air-dried preserved female donkey genital tract. Abbreviations: V, vagina; U, uterus; C, cervix; B, urinary bladder; Ur, urethrae. B: photograph of an air-dried preserved stomach of a goat. 1, left longitudinal ruminal groove; 2, caudal ruminal groove. Abbreviations: S, spleen; Drs, dorsal ruminal sac; Ds, dorsocaudal blind sac; Vrs, ventral ruminal sac; Vs, ventrocaudal blind sac.

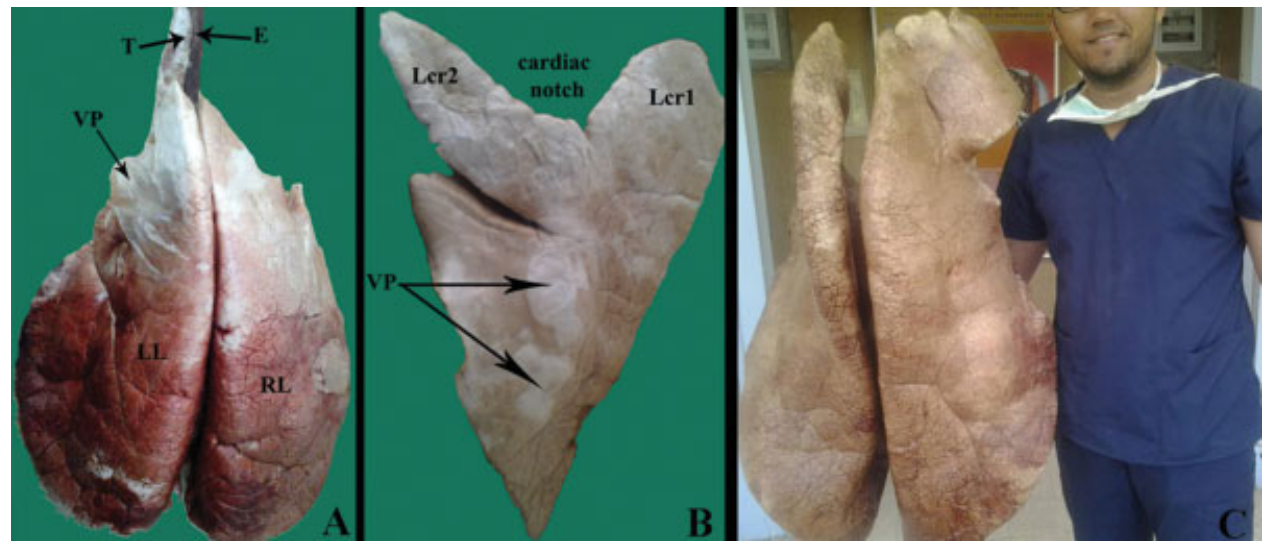

Fig. 8 A: photograph of an air-dried preserved left lung of a goat to show the lobation of the lung. Abbreviations: Vp, Visceral pleura; Lcr1, Left cranial part of cranial lobe; Lcr2, Left caudal part of cranial lobe; Lcd, Left caudal lobe. B: photograph of an air-dried preserved horse lung to show the lobation of the lung and the visceral pleura. Abbreviations: E, Esophagus; T, Trachea; Vp, Visceral pleura. C: photograph to clarify that the preserved lung is stable, has a clean surface, no odor, is extremely durable, maintains its original size, is dry to the touch, free from any greasy residue, and is lighter than in its natural state. 


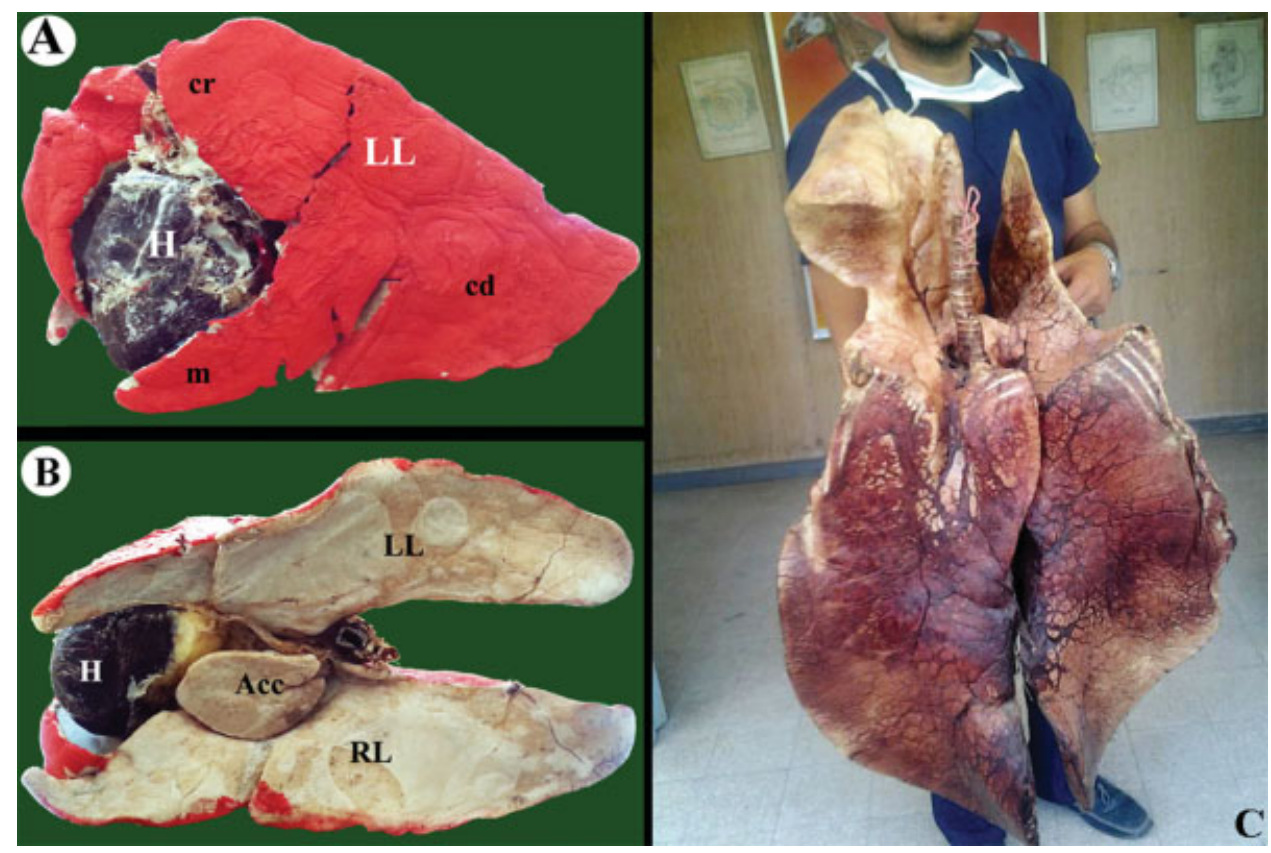

Fig. 9 Photograph of the dorsal surface of an air-dried preserved goat lung. View A: Abbreviations: H, heart; LL, Left lung; cr, Cranial lobe; m, Middle lobe; cd, Caudal lobe, B, Urinary bladder; Ur, Urethra. View B: Abbreviations: H, Heart; LL, Left lung; RL, Right lung; Acc, Accessory lobe. View C: to clarify that the preserved goat lung is stable, has a clean surface, no odor, is extremely durable, maintains its original size, is dry to the touch, free from any greasy residue, and is lighter than in its natural state.

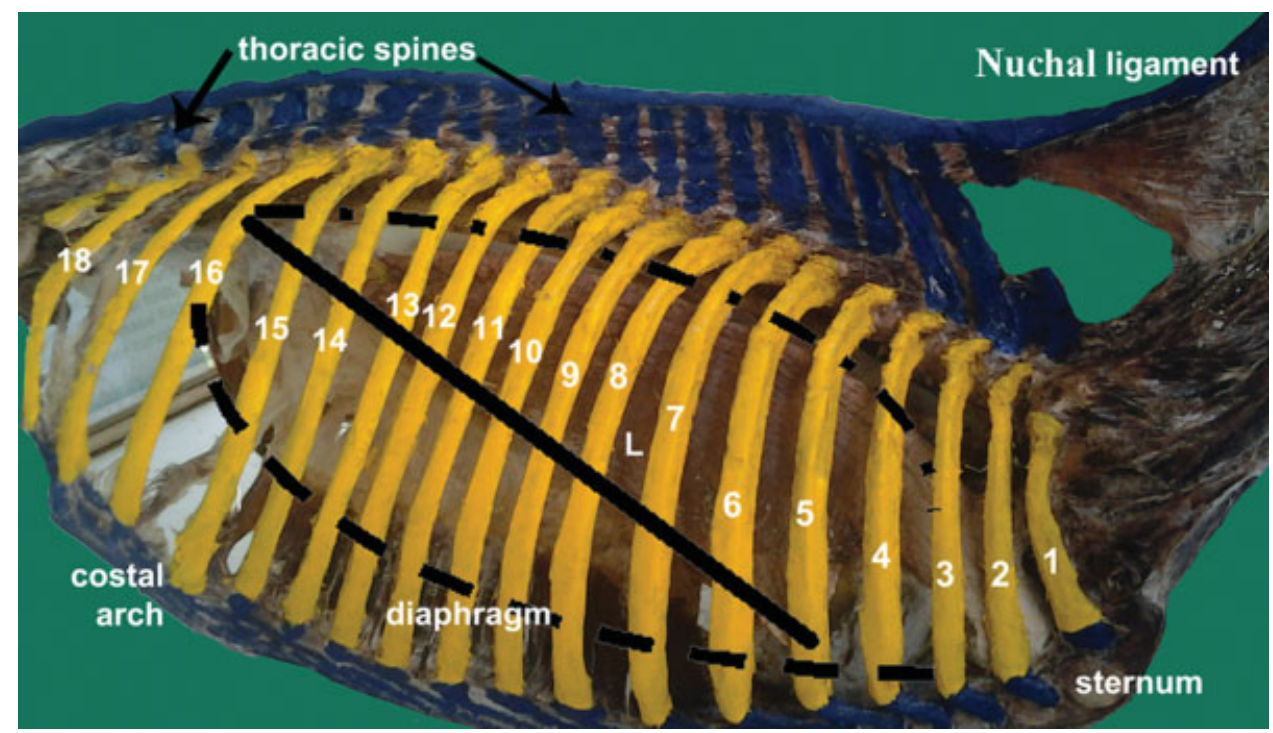

Fig. 10 Photograph of the thoracic cavity of a horse to show the topographic position of the lungs and the area of lung auscultation (the zone marked in black indicates the area of lung auscultation). 1 to 18 , ribs. Abbreviation: L, ILung.

can be made to display certain internal structures, such as the ruminal papillae of the ruminant stomach.

The results of the present study have confirmed that the continuous flow of air accelerates the drying process, rendering the surface of the preserved organs dry, as noted by Arnautovic et al. ${ }^{32}$ Finally, we recommend removing all fat and excessive connective tissue from the preserved organs prior to the beginning of the preservation process, otherwise the surface of the specimens will become greasy, resulting in difficulty to apply the varnish or paint on their external surface.
In anatomical laboratories, students and instructors face many problems when handling and studying the large animal gastrointestinal tracts, especially adult ruminant stomachs, because of their heavy weight and wall flaccidity; moreover, when the gastrointestinal tract is removed from the abdominal cavity and emptied of ingesta, almost all reference anatomical points are lost, but the method described in the present study has solved this problem.

The present study represents the first attempt to study the topographic anatomical position of the lungs in the thoracic cavity of the trunk of donkeys, which will help to determine 
the normal topographic position of the lungs and the area of auscultation and percussion; in addition, it will help the anatomists to demonstrate the relationship of the lungs with their surrounding structures, such as the ribs, the sternum, the heart and the diaphragm.

Finally, the authors of the current study recommend that the professionals in developing countries use the air-drying method for the preservation of the lungs and hollow organs due to its many advantages; the specimens produced through this method maintain their normal anatomical form, are durable, inexpensive to produce, very light in weight, and non-toxic regarding handling; they are also resistant to improper handling and to deterioration by fungi or bacteria. Moreover, through this method, all reference anatomical structures remain very clear, and the preserved specimen lasts for many years without any changes, as noted by Arnautovic et al. ${ }^{32}$ The major disadvantage of the airdrying method is that it can only be used for the lungs and hollow organs.

\section{Conclusion}

The present study described the air-drying method of preserving the hollow organs of different animals. After they have been dried, expanding foam is injected into the lumen of the organs, and then varnish is applied to their external surface to protect them from insect damage.

This method of preservation is suitable for developing countries because it is very cheap to prepare, simple to perform, and can be performed at room temperature $\left(37^{\circ}-40^{\circ} \mathrm{C}\right)$ without special equipment. The specimens produced through this method have many advantages: they maintain their normal anatomical form, are durable, inexpensive to produce, very light in weight, and non-toxic regarding handling; they are also resistant to improper handling and to deterioration by fungi or bacteria. Moreover, through this method, all reference anatomical structures remain very clear, and the preserved specimen lasts for many years without any changes.

Conflicts of interest

The authors have none to declare.

\section{Acknowledgments}

The authors would like to thank all of the staff members of the Department of Anatomy and Embryology, Faculty of Veterinary Medicine, Alexandria University.

\section{References}

1 Rorigues H. Técnicas anatômicas. 3rd ed. Vitória: Arte Visual; 2005

2 von Hagens G, Tiedemann K, Kriz W. The current potential of plastination. Anat Embryol (Berl) 1987;175(04):411-421

3 Henry RW, Butler J. Room-temperature "forced air" impregnation of dried lung with S10/S3-xylene mix. J Int Soc Plastination 1990; 4(14-15):

4 Holladay S. Plastination of inflated hollow gastrointestinal organs from large animals. J Int Soc Plastination 1989;3(01):34-37
5 O'Sullivan E, Stewart IJ. Freeze-dried specimens for gross anatomy teaching. J Anat 1999;195(Pt 2):309

6 Church DC. A simple method for preserving the ruminant stomach. J Anim Sci 1968;27:1525-1526

7 Kitchel RL, et al. Fiberglass technique of preparation of natural models of the ruminant stomach. In J Am Vet Med Assoc1961

8 Correa WR. Isolamento e identificação de fungos filamentosos encontrados em peças anatômicas conservadas em solução de formol a 10\%. São José dos Campos: Universidade do Vale do Paraíba, 59 p. [Dissertação de Mestrado em Ciências Biológicas]. 2003

9 Main DM, Hogan TJ. Health effects of low-level exposure to formaldehyde. J Occup Med 1983;25(12):896-900

10 Giordano C, Siccardi E, Fedrighini B, et al. [Nasal patency patterns observed during working hours in a group of technicians habitually exposed to formaldehyde]. Acta Otorhinolaryngol Ital 1995; 15(05):335-344

11 Kilburn KH, Warshaw R, Thornton JC. Pulmonary function in histology technicians compared with women from Michigan: effects of chronic low dose formaldehyde on a national sample of women. Br J Ind Med 1989;46(07):468-472

12 Sterling TD, Weinkam JJ. Reanalysis of lung cancer mortality in a National Cancer Institute Study on "Mortality among industrial workers exposed to formaldehyde". Exp Pathol 1989;37 (1-4):128-132

13 Taskinen HK, Kyyrönen P, Sallmén M, et al. Reduced fertility among female wood workers exposed to formaldehyde. Am J Ind Med 1999;36(01):206-212

14 International Agency for Research on Cancer. I., Formaldehyde, 2-butoxyethanol and 1-tert-butoxypropan-2- ol. IARC Monographs on the Evaluation of Carcinogenic Risks to Humans, vol. 88. 2006

15 Agency for Toxic Substances and Disease Registry. Toxicological Profile For Formaldehyde. Public Health Service; 1999:165-7

16 McLaughlin JK. Formaldehyde and cancer: a critical review. Int Arch Occup Environ Health 1994;66(05):295-301

17 Jones DG. Reassessing the importance of dissection: a critique and elaboration. Clin Anat 1997;10(02):123-127

18 Hubbell DS, Dwornik JJ, Alway SE, Eliason R, Norenberg RE. Teaching gross anatomy using living tissue. Clin Anat 2002;15 (02):157-159

19 Snelling J, Sahai A, Ellis H. Attitudes of medical and dental students to dissection. Clin Anat 2003;16(02):165-172

20 Nnodim JO, Ohanaka EC, Osuji CU. A follow-up comparative study of two modes of learning human anatomy: by dissection and from prosections. Clin Anat 1996;9(04):258-262

21 McLachlan JC, Bligh J, Bradley P, Searle J. Teaching anatomy without cadavers. Med Educ 2004;38(04):418-424

22 Hariri S, Rawn C, Srivastava S, Youngblood P, Ladd A. Evaluation of a surgical simulator for learning clinical anatomy. Med Educ 2004; 38(08):896-902

23 Holger J, Hollinderbaumer A. On the use and value of new media and how medical students assess their effectiveness in learning anatomy. Anat Rec. Part B 2004;280:20-29

24 Mizer LA, Farnum CE, Schenck PD. The Modular Resource Center: integrated units for the study of the anatomical sciences in a problem-based curriculum. Anat Rec 2002;269(06):249-256

25 Dixit D. Role of standardized embalming fluid in reducing the toxic effects of formaldehyde. Indian Journal of Forensic Medicine \& Toxicology 2008;2(01):1-6

26 Directive 98/8/EC of the European Parliament and of the Council, concerning the placing of biocidal products on the market. OJEU L123, 24.04.1998, p.1-63. (consolidated version to 2008-09-26). 16 February 1998

27 Commission Regulation (EC) No. 2032/2003, on the second phase of the 10-year work programme referred to in Article 16(2) of Directive 98/8/EC of the European Parliament and of the Council concerning the placing of biocidal products on the market, and 
amending Regulation (EC) No 1896/2000. OJEU L307, 24.11.2003, p.1-96. (consolidated version to 2007-01-04). 4 November 2003.

28 Mckiernan BC, Kneller SK. A simple method for the preparation of inflated air-dried lung specimens. Vet Rad 1983;24(02): 58-62

29 von Hagens G. Heidelberg plastination folder. Collection of all technical leaflets for plastination. 2nd Ed. Heidelberg: Anatomische Institut, Universität; 1986
30 Henry WR, Janick L, Henry C. Specimen preparation for silicone plastination. J Int Soc Plastination 1997;12(01):13-17

31 Sivagnanam S, et al. The Epoxy Resin Plastination of Reproductive Organs of Animals. Asian Journal of Science and Technology 2014; 5(03):181-182

32 Arnautovic I, et al. Improved method for dried anatomical specimen preparation. Journal of the International Society for Plastination 2005;20:13-15 